\title{
Pengembangan Panduan Mendesain Konten E-learning Pada Platform Totara
}

\author{
Maharani Eka Pratiwi ${ }^{\bowtie}$, R.A Murti Kusuma Wirasti ${ }^{2}$, Kunto Imbar Nursetyo ${ }^{3}$ \\ ${ }^{1}$ Universitas Negeri Jakarta, Jakarta, Indonesia. \\ 2 Universitas Negeri Jakarta, Jakarta, Indonesia. \\ 3 Universitas Negeri Jakarta, Jakarta, Indonesia. \\ DOI: https://doi.org/10.21009/JPI.o12.05
}

\begin{abstract}
Article History
Received : 2018/o8

Accepted : 2018/o8

Published : 2018/o8

Keywords

panduan; desain; course content; $e$ learning; totara; rowntree; media cetak.

Abstract

Penelitian pengembangan ini bertujuan menghasilkan panduan mendesain konten $e$ learning secara umum dan khusus pada platform Totara. Panduan dikemas dalam media cetak berbentuk buku dan leaflet. Sasaran pengguna panduan ini ialah dosen di FIP UNJ. Penelitian pengembangan ini dilakukan berdasarkan model Rowntree yang memiliki tiga tahapan besar yakni tahap perencanaan, tahap persiapan penulisan, serta tahap penulisan dan penyuntingan. Evaluasi pada penelitian pengembangan ini dilakukan melalui expert review dan face-to-face tryouts. Evaluasi tersebut melibatkan 1 orang ahli materi, 1 orang ahli media, dan 3 orang pengguna. Nilai rata-rata yang diperoleh dari tahap expert review oleh ahli materi ialah 3,6 dan menunjukkan kategori sangat baik. Nilai rata-rata yang diperoleh dari tahap expert review oleh ahli media ialah 3,1 dan menunjukkan kategori baik. Pada tahap face-toface tryouts, diperoleh nilai rata-rata 3,8 yang menandakan secara keseluruhan panduan ini sangat baik dan dapat digunakan untuk memandu dosen dalam mendesain konten e-learning, khususnya pada platform Totara dengan baik.
\end{abstract}

\begin{abstract}
The development research aims to produce a guidelines for designing e-learning content in general and spesific in Totara platform. The guides are packed in a printed book and leaflet. This guidelines is meant to be used by lecturer in FIP UNJ. This development research is referring to Rowntree's model that consists of three major stages; planning; preparation of writing; writing and editing. The evaluation on this development research was conducted through expert review and face-to-face tryouts. The evaluation involving one subject matter expert, one media expert, and three users. The average value obtainded from the expert review by the subject matter expert was 3,6 overall excellent. The average value obtainded from the expert review by the media expert was 3,1 overall good. In face-to-face tryouts, obtained the average score 3,8 which signifies the overall guidance is excellent and can be used to guide lecturer in designing elearning content, spesifically in Totara platform.
\end{abstract}




\section{PENDAHULUAN}

Kehadiran e-learning berbasis web dalam dunia pendidikan di Indonesia sudah bukan merupakan satu hal yang baru lagi saat ini. Kehadirannya banyak membawa manfaat dan kemudahan bagi lembaga pendidikan untuk memberikan akses pendidikan kepada peserta didik melalui pembelajaran jarak jauh. Kemudahan akses yang ditawarkan oleh $e$ learning ini menjadi daya tarik tersendiri bagi peserta didik yang mayoritas berkarakter sebagai digital native. E-learning dinilai dapat mengakomodir kebutuhan gaya belajar digital native, maka tak ayal jika saat ini e-learning berbasis web dimanfaatkan oleh banyak lembaga pendidikan, mulai dari jenjang Sekolah Menengah hingga Perguruan Tinggi.

Salah satu Perguruan Tinggi yang telah mengembangkan dan memanfaatkan $e$ learning berbasis web ialah Universitas Negeri Jakarta (UNJ), khususnya di Program Studi Teknologi Pendidikan, Fakultas Ilmu Pendidikan (Prodi TP FIP). Tahun 2017, Prodi TP FIP UNJ kembali mengembangkan sebuah e-learning berbasis web untuk digunakan oleh seluruh Prodi di Fakultas Ilmu Pendidikan. Elearning berbasis web ini disematkan ke dalam website resmi UNJ yaitu http://fip.unj.ac.id/hylearn. Pengembangan elearning berbasis web ini menggunakan platform Learning Content Management System (LCMS) yang bernama Totara. Seperti namanya, hylearn diharapkan dapat menjadi wadah untuk memfasilitasi terlaksananya hybrid learning pada proses perkuliahan mahasiswa di FIP UNJ.

Seiring dengan pengembangannya, ditemukan beberapa kendala yang berpotensi akan menghambat penggunaan hylearn, diantaranya kekhawatiran Dosen apabila tidak mampu menggunakan e-learning dengan maksimal dikarenakan kurangnya pengetahuan mengenai konsep e-learning yang sesungguhnya, bagaimana mendesain konten e-learning agar tepat guna, serta minimnya pengalaman menggunakan e-learning dalam proses perkuliahan.

Melihat kendala tersebut, terdapat beberapa faktor penyebab masalah yang pengembang temukan berdasarkan hasil studi pendahuluan antara lain yaitu; 1) perbedaan metode dan strategi pembelajaran yang digunakan antara proses perkuliahan berbasis web dengan perkuliahan tatap muka, 2) pengembangan konten e-learning yang tidak mudah, karena bukan semata-mata memindahkan materi ajar ke dalam bentuk digital, melainkan perlu menimbulkan interaksi belajar pada mahasiswa, 3) karakteristik usia Dosen FIP UNJ yang mayoritas berusia 30 - 60 tahun, sehingga tergolong sebagai digital immigrant, menyebabkan keterampilan penggunaan perangkat digitalnya standar dan cenderung kurang, 4) rendahnya tingkat pengetahuan dosen di FIP UNJ mengenai e-learning, 5) belum adanya sebuah media yang mendokumentasikan pengetahuan terkait cara mendesain konten dalam sebuah e-learning..

Berdasarkan definisi Teknologi Pendidikan (TP) yang dikemukakan oleh Association for Educational Communication Communication and Technology (AECT) pada tahun 2004, yaitu :

Educational technology is the study and ethical practice of facilitating learning and improving performance by creating, using and managing appropriate technological processes and resources

Sesuai dengan definisi tersebut, TP dapat berperan dalam memecahkan masalah belajar yang dihadapi oleh Dosen FIP UNJ sebagaimana yang telah diuraikan pada beberapa faktor penyebab masalah di atas. Pemecahan masalah belajar tersebut dapat dilakukan dengan salah satu intervensi yang ditawarkan oleh Teknologi Pendidikan pada kawasan creating, yaitu menciptakan prosesproses atau sumber-sumber teknologi yang tepat guna untuk memfasilitasi belajar dan meningkatkan kinerja belajar.

Berdasarkan masalah dan penjelasan di atas, maka pengembang terdorong untuk mengembangkan sebuah panduan bagi Dosen FIP UNJ untuk mendesain konten e-learning. Panduan dikemas dalam bentuk media cetak yaitu buku dan leaflet. Pemilihan media cetak ini berdasarkan hasil data studi pendahuluan dan analisis materi yang dilakukan oleh pengembang. Dari hasil studi pendahuluan dan analisis materi tersebut, ditemukan beberapa hal antara lain : 1) karakteristik dosen FIP UNJ yang mayoritas ialah seorang digital immigrant membuat mereka lebih nyaman dan memilih 
menggunakan sebuah media cetak, 2) materi yang akan disampaikan terkait panduan mendesain konten e-learning ini harus spesifik, sehingga membutuhkan sebuah media yang terdiri dari beberapa sub untuk menjelakan detailnya, 3) dibutuhkan sebuah media yang merangkum secara singkat panduan teknis terkait mendesain konten di e-learning FIP UNJ yaitu hylearn yang menggunakan platform Totara.

Penelitian pengembangan panduan serupa sebelumnya telah dilakukan oleh Hanim, Puwaningsih dan Widjianto (2014), tetapi lebih berfokus pada blended learning yang dilakukan dalam pembelajaran fisika, bukan proses perancangan konten e-learning di web based learning yang digunakan. Selain itu, penelitian tersebut juga berfokus dengan platform Moodle, dan masih sangat sedikit penelitian e-learning yang membahas tentang platform Totara.

Pengembangan ini penting dilaksanakan karena dapat mengurangi risiko kegagalan Dosen untuk mencapai tujuan pembelajaran yang diselenggarakan melalui hylearn karena tidak memiliki pengetahuan tentang cara mendesain konten e-learning. Hal ini disebabkan mendesain konten e-learning harus dilakukan secara spesifik dan fokus agar mahasiswa yang akan belajar menggunakan $e$ learning ini dapat berinteraksi dengan materi ajar dengan maksimal, sehingga proses belajar mandiri benar-benar terjadi karena tidak sekedar membaca sekilas dan selesai. Dengan demikian, dibutuhkan sebuah panduan guna memberi petunjuk atau arahan kepada Dosen untuk mendesain konten e-learning. Demi terlaksananya hybrid learning pada hylearn yang menggunakan platform Totara, maka harus dipastikan semua Dosen mampu memanfaatkan e-learning semaksimal mungkin, disamping melaksanakan pembelajaran tatap muka di dalam kelas.

Artikel ini menguraikan proses pengembangan panduan mendesain konten $e$ learning untuk dosen di Fakultas Ilmu Pendidikan, Universitas Negeri Jakarta. Pengembangan ini diharapkan dapat berguna secara teoritis karena menjelaskan mengenai proses pengembangan panduan mendesain konten e-learning di sebuah lembaga, serta dapat pula dijadikan referensi bagi pengembangan serupa dikemudian hari agar terlaksana secara lebih baik dan mendalam. Selain itu, hasil produk pengembangan ini yang berupa buku dan leaflet, dapat digunakan oleh pihak lembaga untuk memfasilitasi belajar para Dosen terkait mendesain konten e-learning dan menjadi aset lembaga yakni dokumentasi pengetahuan mengenai e-learning.

\section{METODE}

Penelitian ini merupakan penelitian pengembangan menggunakan model pengembangan yang dikemukakan oleh Derek Rowntree. Model pengembangan Rowntree terdiri dari tiga tahapan besar yaitu: tahap perencanaan, tahap persiapan penulisan, tahap penulisann dan penyuntingan.

Penelitian ini dilaksanakan di Fakultas Ilmu Pendidikan, Universitas Negeri Jakarta (FIP UNJ). Adapun durasi penelitian dilakukan selama 7 bulan dimulai dari bulan Januari hingga Juli 2018, dengan sasaran penelitian yaitu dosen di FIP UNJ. Dosen yang dijadikan sasaran penelitian ini dipilih dari perwakilan tujuh program studi yang ada di FIP UNJ.

Pengembangan panduan mendesain konten e-learning ini melibatkan satu orang pengkaji materi, satu orang pengkaji media dan tiga orang pengguna. Teknik evaluasi yang digunakan ialah expert review dan face-to-face tryouts. Pada tahap evaluasi, digunakan kuesioner sebagai instrumen peelitian. Kuesioner yang dibuat menggunakan skala 1-4 untuk menilai aspek-aspek sebagai berikut: 1) materi/konten, 2) karakteristik panduan, 3) visual, 4) verbal, 5) tipografi, 6) fisik buku, 7) fisik leaflet. Untuk mengolah data yang diperoleh melalui kuesioner, digunakan teknik analisis data menggunakan rumus statistik sederhana untuk mengetahui skor rata-rata yang selanjutnya dianalisis secara deskriptif untuk mengambil kesimpulan.

\section{HASIL DAN PEMBAHASAN}

Pengembangan panduan ini dilakukan melalui tiga tahap sesuai dengan model pengembangan Rowntree (1994), dengan penjabaran hasil sebagai berikut:.

\section{A. Tahap Perencanaan}

Pada tahap ini pengembang melakukan analisis karakteristik pengguna 
bahan ajar untuk menggali informasi awal tentang profil calon pengguna panduan mendesain konten e-learning ini, yaitu dosen di ketujuh prodi FIP UNJ. Analisis ini juga dilaksanakan dengan maksud agar panduan yang dikembangkan sesuai dengan karakteristik penggunanya. Analisis ini dilakukan dengan menyebarkan kuesioner yang berisi 11 butir pertanyaan kepada 12 orang responden yang merupakan perwakilan dosen dari tujuh program studi di FIP UNJ. Adapun hasil yang diperoleh yaitu profil karakter pengguna bahan ajar sebagai berikut:

Tabel 1 Profil Pengguna Panduan

\begin{tabular}{|c|c|}
\hline Aspek & Deskripsi \\
\hline Demografi & $\begin{array}{l}\text { - Rentang usia Dosen FIP } \\
\text { UNJ } 25 \text { - } 57 \text { tahun } \\
\text { - Hambatan belajar yang } \\
\text { dimiliki oleh mayoritas } \\
\text { dosen di FIP UNJ ialah } \\
\text { terbatasnya pengetahuan } \\
\text { tentang e-learning, serta } \\
\text { minimnya pengalaman } \\
\text { mendesain konten e- } \\
\text { learning } \\
\text { - Seluruhnya termasuk ke } \\
\text { dalam golongan } \\
\text { ekonomi menengah ke } \\
\text { atas } \\
\text { - Telah memiliki } \\
\text { kemampuan } \\
\text { penggunaan komputer } \\
\text { dan internet }\end{array}$ \\
\hline $\begin{array}{l}\text { Latar } \\
\text { Belakang } \\
\text { Bidang Studi }\end{array}$ & 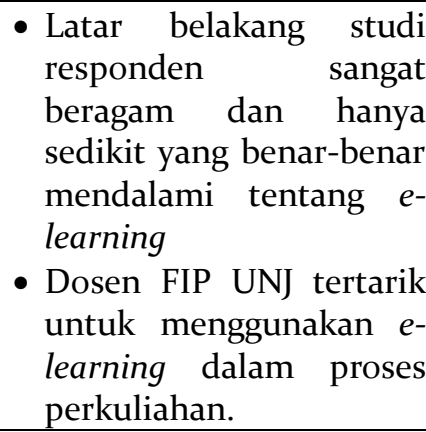 \\
\hline Motivasi & \begin{tabular}{lrr} 
- Motivasi & \multicolumn{2}{r}{ pengguna } \\
untuk menggunakan \\
panduan yaitu karena \\
memiliki & keterkaitan \\
yang sangat erat dengan \\
profesi dosen dan \\
kewajibannya dalam \\
memfasilitasi mahasiswa
\end{tabular} \\
\hline
\end{tabular}

\begin{tabular}{|c|c|}
\hline $\begin{array}{l}\text { Faktor } \\
\text { Belajar }\end{array}$ & $\begin{array}{l}\text { - Kemampuan belajar } \\
\text { dosen FIP UNJ tergolong } \\
\text { tinggi, serta memiliki } \\
\text { gaya belajar yang dapat } \\
\text { menyesuaikan, } \\
\text { walaupun mayoritas } \\
\text { lebih nyaman dengan } \\
\text { gaya belajar visual. }\end{array}$ \\
\hline $\begin{array}{l}\text { Faktor } \\
\text { Sumber } \\
\text { Belajar }\end{array}$ & $\begin{array}{l}\text { - Dari segi waktu belajar, } \\
\text { mayoritas mengatakan } \\
\text { bahwa tidak memiliki } \\
\text { jumlah waktu tertentu } \\
\text { untuk belajar hal baru, } \\
\text { karena waktu luangnya } \\
\text { cenderung sedikit dan } \\
\text { tidak menentu } \\
\text { - Dari segi fasilitas dan } \\
\text { akses terhadap sumber } \\
\text { belajar yang ada sangat } \\
\text { melimpah, karena } \\
\text { lingkungan profesinya } \\
\text { pun ada di sebuah } \\
\text { kampus yang memiliki } \\
\text { banyak sumber belajar, } \\
\text { seperti halnya } \\
\text { perpustakaan, komputer } \\
\text { dengan jaringan } \\
\text { internet, dsb }\end{array}$ \\
\hline
\end{tabular}

Selanjutnya, pengembang juga merumuskan tujuan umum dan khusus panduan sebagai berikut :

\section{Tujuan Pembelajaran Umum:}

Setelah mempelajari materi pada buku panduan ini, pengguna dapat mendesain konten e-learning dengan benar sesuai dengan kaidah yang berlaku.

\section{Tujuan Pembelajaran Khusus:}

1. Pengguna dapat menjelaskan $e$ learning yang digunakan di FIP UNJ

2. Pengguna dapat mengidentifikasi tahapan desain konten e-learning

3. Pengguna dapat merancang konten $e$ learning konten e-learning pada mata kuliah tertentu dengan tepat.

Pengembang mengembangkan media dengan mengadopsi dari bahan ajar yang sudah ada yaitu Bahan Ajar Lokakarya Content Design of Web Based Learning yang dikembangkan oleh Dewi S. Prawiradilaga, Murti K. Wirasti, Eveline 
Siregar, Suprayekti, Kunto Imbar N dan Diana Ariani pada tahun 2011. Namun, tentunya dengan beberapa modifikasi agar lebih sesuai dengan platform LCMS yang digunakan.

Pengembang menyusun garis besar isi panduan mendesain konten e-learning sebagai berikut :

Tabel 2 Garis Besar Isi Buku Panduan

\begin{tabular}{|c|c|c|c|}
\hline $\begin{array}{c}\text { Tujuan } \\
\text { Pembelajar } \\
\text { an Khusus }\end{array}$ & $\begin{array}{c}\text { Pokok } \\
\text { Bahasan }\end{array}$ & $\begin{array}{c}\text { Sub Pokok } \\
\text { Bahasan }\end{array}$ & Pustaka \\
\hline $\begin{array}{l}\text { Mengidentifi } \\
\text { kasi tahapan } \\
\text { desain } \\
\text { konten e- } \\
\text { learning }\end{array}$ & $\begin{array}{l}\text { Tahapan } \\
\text { Mendesai } \\
\text { n Konten } \\
\text { e- } \\
\text { learning }\end{array}$ & 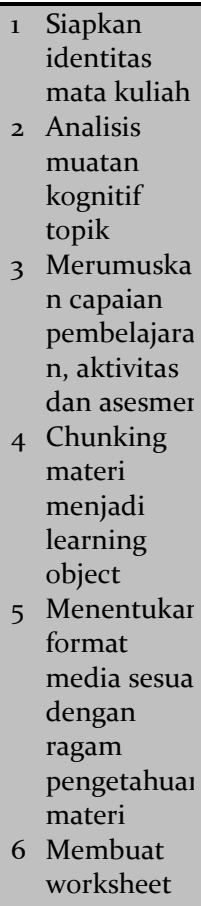 & $\begin{array}{l}\text { Buku Mozaik } \\
\text { Teknologi } \\
\text { Pendidikan : } \\
\text { E-learning, } \\
\text { karya, karya } \\
\text { Dewi S } \\
\text { Prawiradilag } \\
\text { a, dkk, } 2013\end{array}$ \\
\hline $\begin{array}{l}\text { Merancang } \\
\text { konten e- } \\
\text { learning } \\
\text { pada mata } \\
\text { kuliah } \\
\text { tertentu } \\
\text { dengan tepat }\end{array}$ & $\begin{array}{l}\text { Men- } \\
\text { desain } \\
\text { Konten } \\
\text { E- } \\
\text { Learning }\end{array}$ & \begin{tabular}{ll}
1 & \multicolumn{1}{c}{$\begin{array}{l}\text { Menuliskan } \\
\text { identitas má } \\
\text { kuliah }\end{array}$} \\
2 & $\begin{array}{l}\text { Memilih } \\
\text { topik, capaii }\end{array}$ \\
pembelajara \\
aktivitas daı \\
asesmen \\
3 Menchunkiı \\
materi \\
menjadi \\
learning \\
object \\
4 \\
Menentukaı \\
format bedi \\
dan \\
menuangka \\
ya dalam \\
worksheet
\end{tabular} & $\begin{array}{l}\text { Buku Mozaik } \\
\text { Teknologi } \\
\text { Pendidikan : } \\
\text { E-learning, } \\
\text { karya, karya } \\
\text { Dewi S } \\
\text { Prawiradilag } \\
\text { a, dkk, } 2013\end{array}$ \\
\hline
\end{tabular}


Panduan ini menggunakan beberapa dukungan grafis berupa ilustrasi, ikon dan gambar sebagai pelengkap atau penjelas materi yang disampaikan, sehingga materi tidak hanya disajikan dalam bentuk teks. Selanjutnya, pengembang mengidentifikasi peralatan yang dibutuhkan dalam proses produksi panduan sebagai berikut :

Tabel 4 Identifikasi Peralatan yang dibutuhkan

\begin{tabular}{|c|c|c|c|}
\hline No & $\begin{array}{c}\text { Nama Alat/ } \\
\text { Komponen Bahan }\end{array}$ & Spesifikasi & Jumlah \\
\hline 1 & Komputer & $\begin{array}{l}\text { - Processor AMD } \\
\text { Radeon R5 } \\
\text { Graphics } \\
\text { - } \text { RAM }_{4} \text { GB } \\
\text { - Drive } 4 \text { GB } \\
\text { - VGA } \\
\text { - Keyboard/ Mouse } \\
\text { - Monitor }\end{array}$ & 1 Unit \\
\hline 2 & Printer & & 1 Unit \\
\hline \multicolumn{4}{|c|}{ Komponen } \\
\hline 1 & $\begin{array}{l}\text { Software } \\
\text { pendukung } \\
\text { Operating System }\end{array}$ & Windows 10 & 1 Paket \\
\hline 2 & $\begin{array}{l}\text { Software Digital } \\
\text { Layouting }\end{array}$ & Adobe In Design & 1 Paket \\
\hline 3 & $\begin{array}{l}\text { Software Digital } \\
\text { Illustration }\end{array}$ & Adobe Illustrator & 1 Paket \\
\hline 4 & $\begin{array}{l}\text { Software Pengolah } \\
\text { Kata }\end{array}$ & $\begin{array}{l}\text { Microsoft Word } \\
2016\end{array}$ & 1 Paket \\
\hline \multicolumn{4}{|c|}{ Bahan } \\
\hline 1 & $\begin{array}{l}\text { Kertas untuk Kulit } \\
\text { Buku }\end{array}$ & Art Karton 250 gr & 1 lembar $A_{3}$ \\
\hline 2 & Kertas HVS & ukuran $\mathrm{B}_{5} 80 \mathrm{gr}$ & 5o lembar \\
\hline 3 & Jilid buku & Soft cover & 1 Pcs \\
\hline
\end{tabular}

Terakhir, pengembang merumuskan bentuk fisik buku yaitu berukuran $\mathrm{B}_{5}$, menggunakan art carton sebagai kertas cover dan hvs sebagai kertas isi, penjilidan soft cover, berjumlah 32 halaman, dicetak penuh warna, menggunakan jenis huruf Coco Gothic Heavy dan TwCenMT yang berukuran 18 pt, 16 pt dan 11 pt. Sedangkan bentuk fisik leaflet yaitu berukuran legal, dicetak pada kertas art carton, berjumlah 2 halaman (bolak-balik), dicetak penuh warna, menggunakan jenis huruf TwCenMT Bold dan TwCenMT CondensedExtraBold yang berukuran 18 pt, 16 pt dan 11 pt.

\section{Tahap Penulisan dan Penyuntingan}

Tahap ini dimulai dengan membuat draf sesuai dengan sistematika yang telah dibuat. Sistematika buku panduan mendesain konten e-learning ialah sebagai berikut:

\section{Sampul Depan}

2. Tim Penyusun

3. Daftar Isi

4. Hylearn FIP UNJ

5. Kemampuan Prasyarat

6. Tujuan Pembelajaran

7. Bagian 1 : Tahapan Mendesain Konten Elearning

a. Flowchart Tahapan Mendesain Konten E-learning

b. Tahap 1 : Siapkan Identitas Mata Kuliah

c. Tahap 2 : Analisis Muatan Kognitif Topik

d. Tahap 3 : Merumuskan Tujuan Pembelajaran, Aktivitas dan Asesmen

e. Tahap 4 : Chunking Materi menjadi Learning Object

f. Tahap 5 : Menentukan Format Media sesuai dengan Ragam Pengetahuan Materi

g. Tahap 6 : Membuat Worksheet

8. Bagian 2 : Mendesain Konten E-learning

a. Tahap 1 : Menuliskan Identitas Mata Kuliah

b. Tahap 2 \& 3 : Pilih Topik, Rumuskan Tujuan Pembelajaran, Aktivitas dan Asesmen

c. Tahap 4 : Chunking Materi menjadi Learning Object

d. Tahap 5 \& 6 : Menentukan Format Media dan Menuangkannya dalam Worksheet

9. Sekilas tentang Platform Totara

10. Glosarium

11. Referensi

Sistematika leaflet panduan mendesain konten e-learning ialah sebagai berikut:

1. Tujuan Pembelajaran

2. Flowchart Log In di Hylearn

3. Flowchart Membuat Coursesite

4. Penerapan Tahapan Mendesain Konten E-learning di Hylearn

a. Mengunggah identitas mata kuliah

b. Menambahkan dan Menyunting Topik Mata Kuliah

c. Mengunggah Rumusan Tujuan Pembelajaran

d. Mengunggah Learning Object sesuai Worksheet.

Setelah menyelesaikan draf, pengembang memasukkan materi berupa 
Maharani Eka Pratiwi et al | JPI/Vol.o1/No.02/2018 | H. 33 - 42

teks, gambar dan ilustrasi yang telah dibuat sebelumnya, berdasarkan urutan dan tata letak yang telah dirancang. Proses melengkapi dan penyuntingan panduan ini dilakukan oleh pengembang berdasarkan masukkan dari ahli materi dan ahli media serta dibimbing oleh dosen pembimbing.

Berikut merupakan contoh desain cover dan layout panduan mendesain konten e-learning :
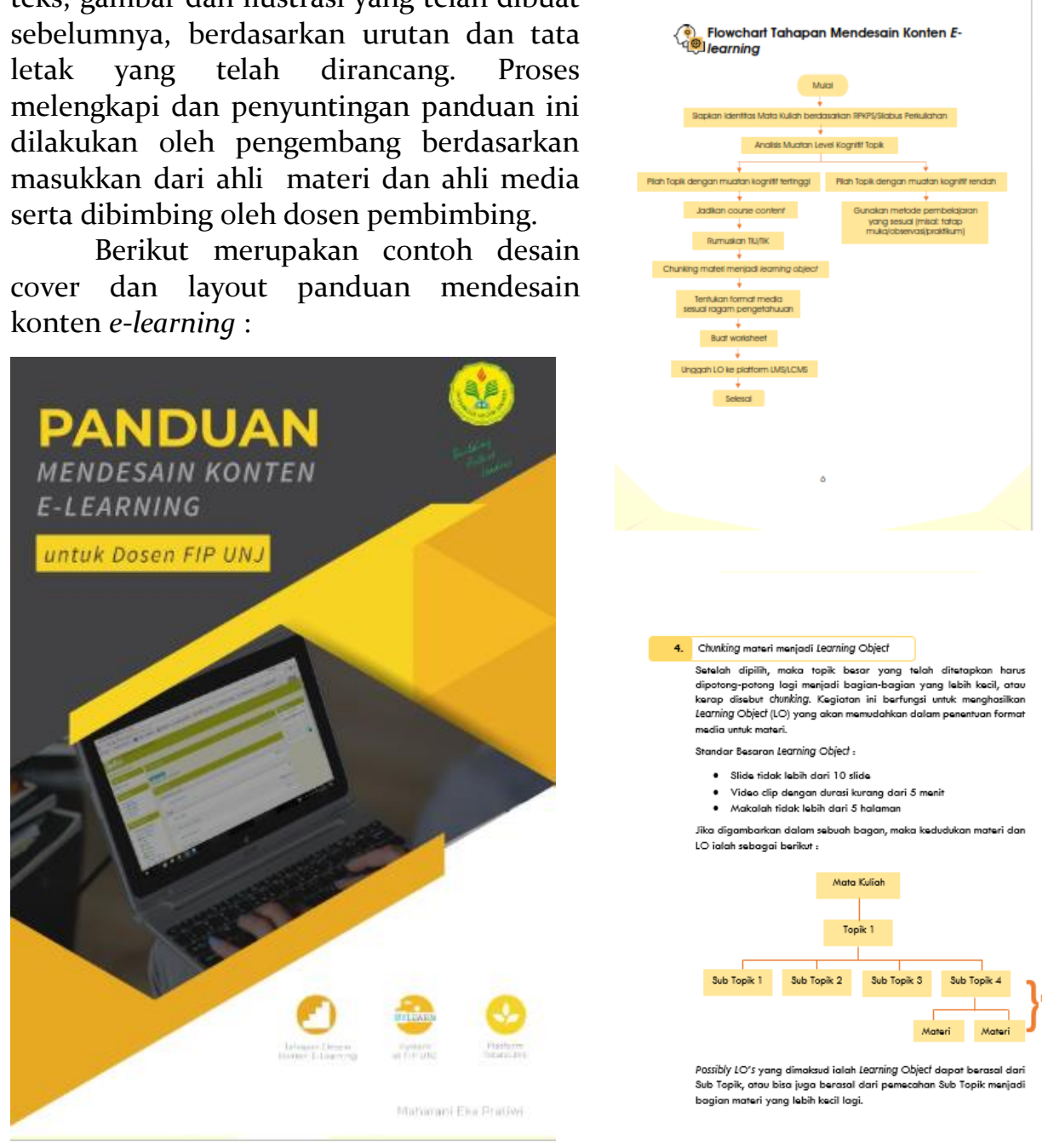

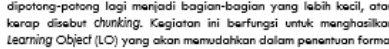
mesia untuk materi.

Standar Bosaran Learning object:

- Slide tidak lobih dori 10 slide
Vidoo clip dengan durass kurang dari 5 menit
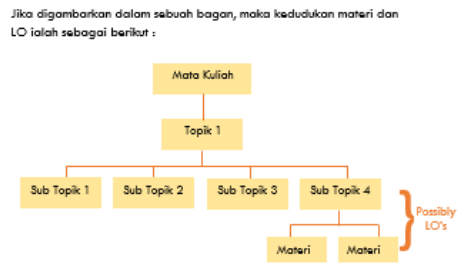

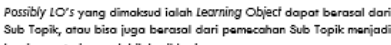

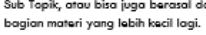

Gambar 1 Desain Cover Buku
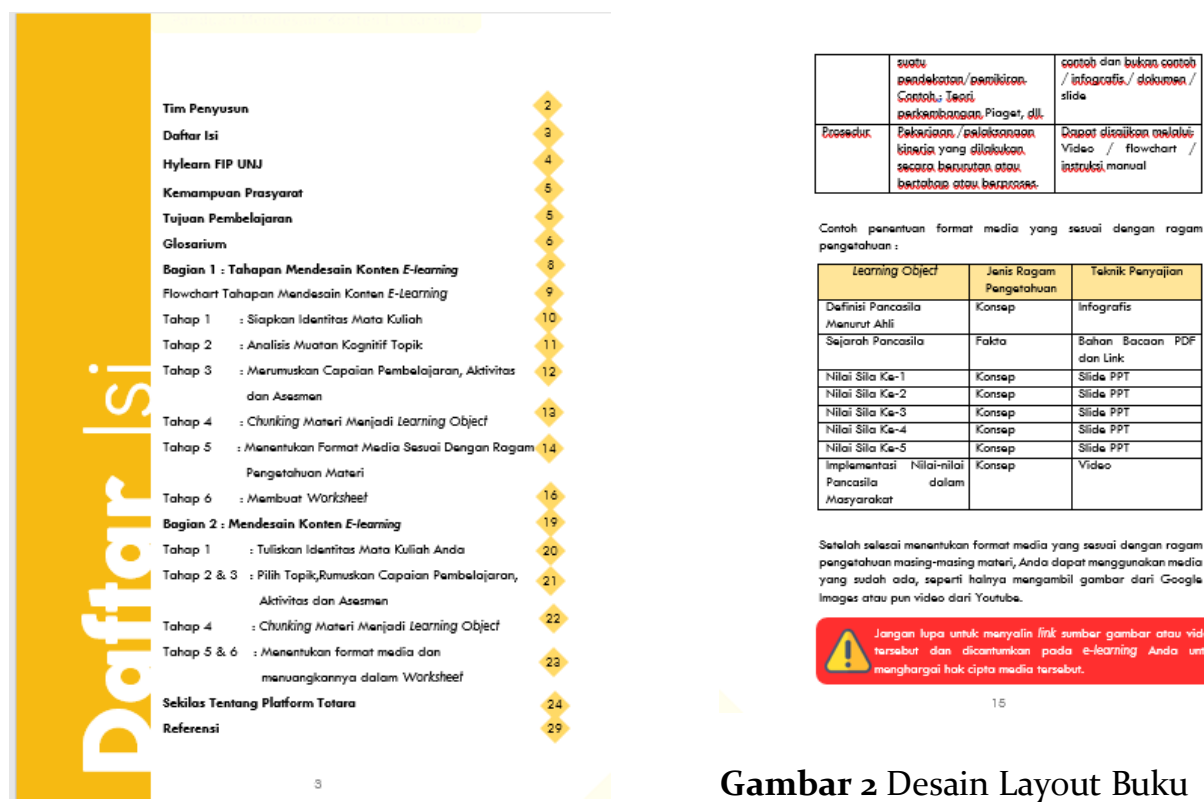

Satcloh solessi menentukan formot media yang sesvai dengan rogan

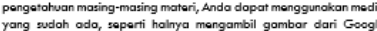
Imoges atau pun video dari Younube.

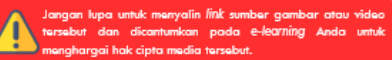

Gambar 2 Desain Layout Buku 


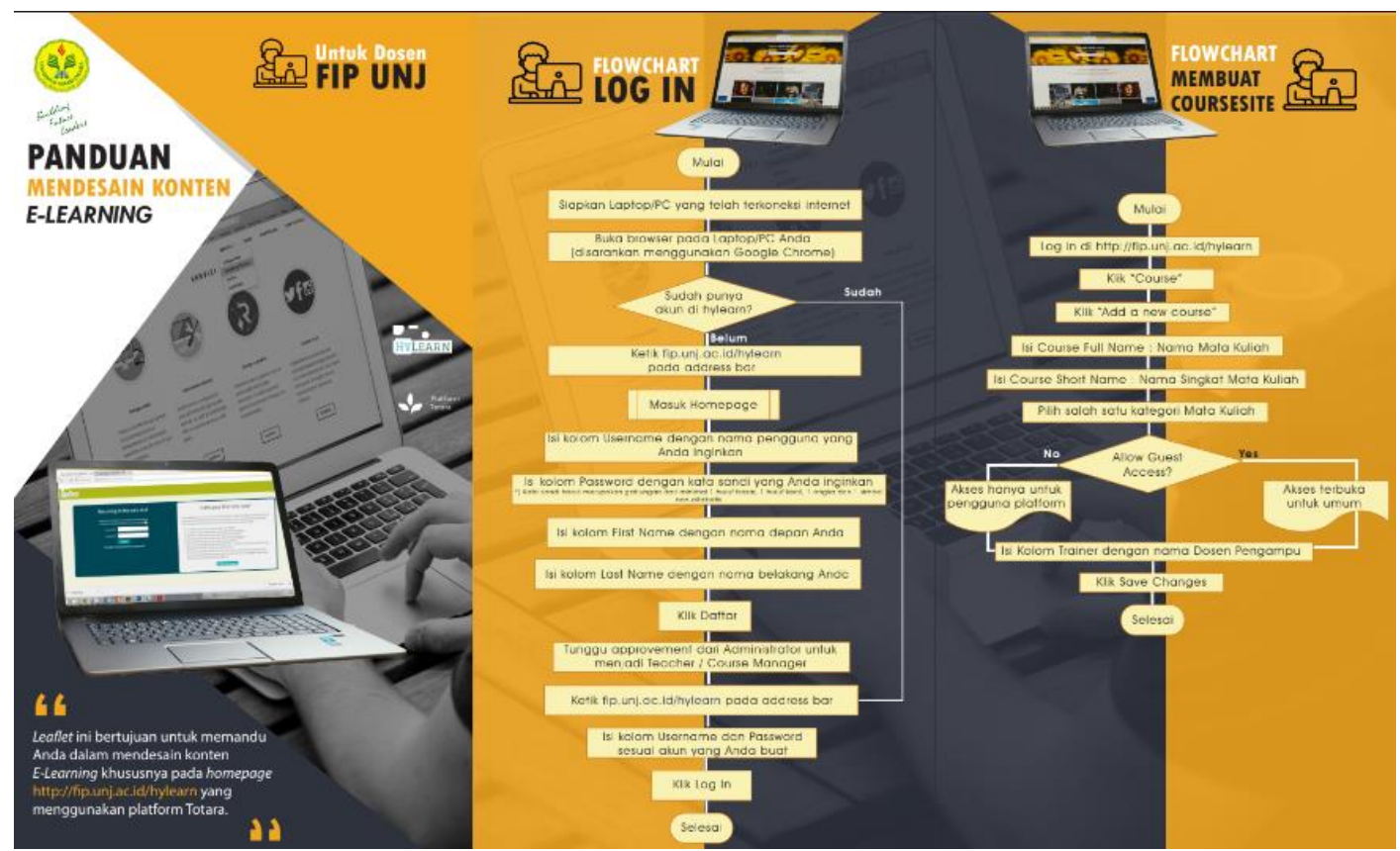

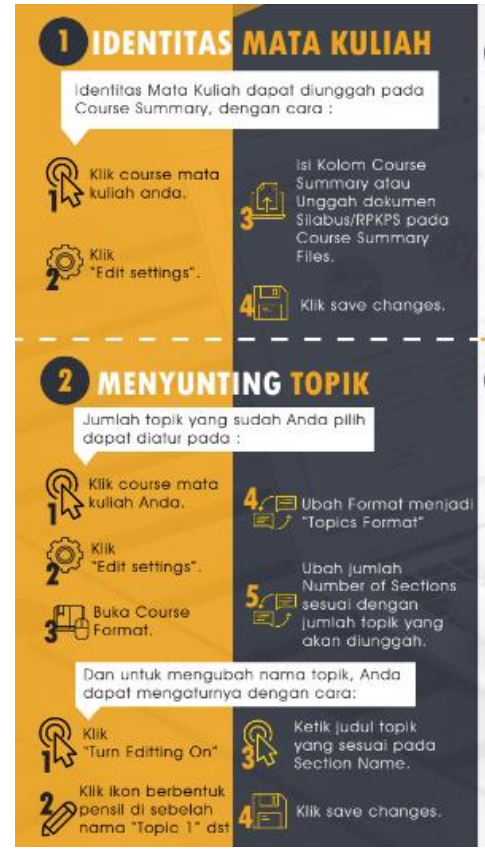

Gambar 3 Desain Leaflet

Terakhir ialah menguji coba dan memperbaiki melalui expert review dan face-to-face tryouts. Expert review dilakukan oleh seorang ahli materi dan seorang ahli media. Hasil expert review tersebut tersaji pada tabel rekapitulasi berikut:
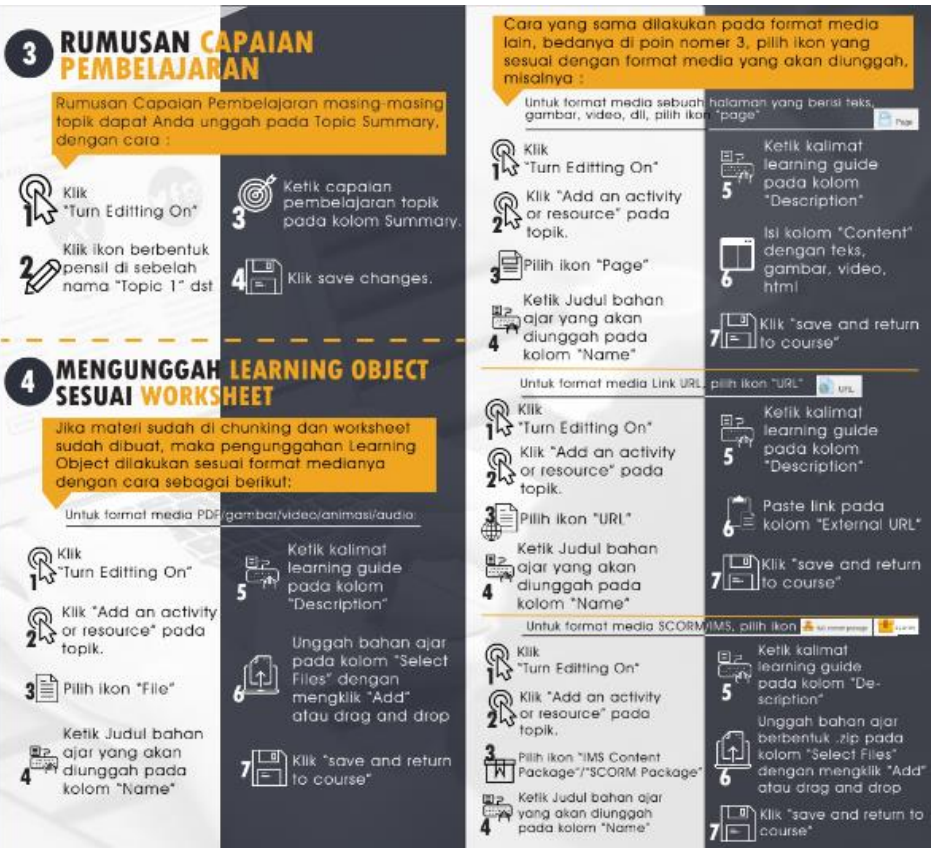

Tabel 5 Rekapitulasi Hasil Expert review

\begin{tabular}{lc}
\hline \multicolumn{1}{c}{ Responden } & Nilai Rata-Rata \\
\hline Ahli Materi & 3,6 \\
Ahli Media & 3,1 \\
Rata-Rata & 3,3 \\
Keseluruhan & \\
\hline
\end{tabular}

Berdasarkan hasil perhitungan serta acuan penilaian di atas, maka hasil nilai rata-rata keseluruhan yang dicapai adalah baik, dengan nilai rata-rata keseluruhan 
sebesar 3,3. Panduan mendesain konten $e$ learning yang dikembangkan telah memiliki kualitas yang baik dalam aspek materi maupun aspek media. Namun, ada beberapa masukan dari ahli materi dan ahli media untuk perbaikan panduan seperti halnya yang tersaji dalam tabel di bawah ini:

Tabel 6 Masukan Para Ahli

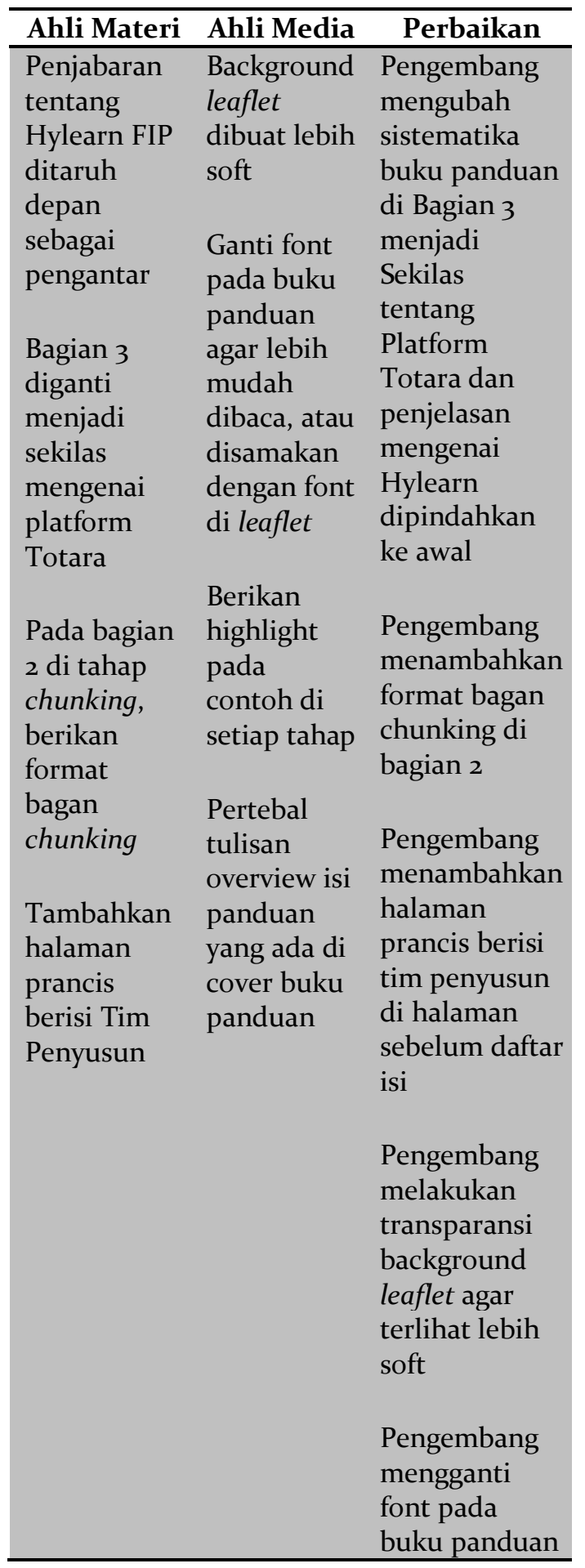

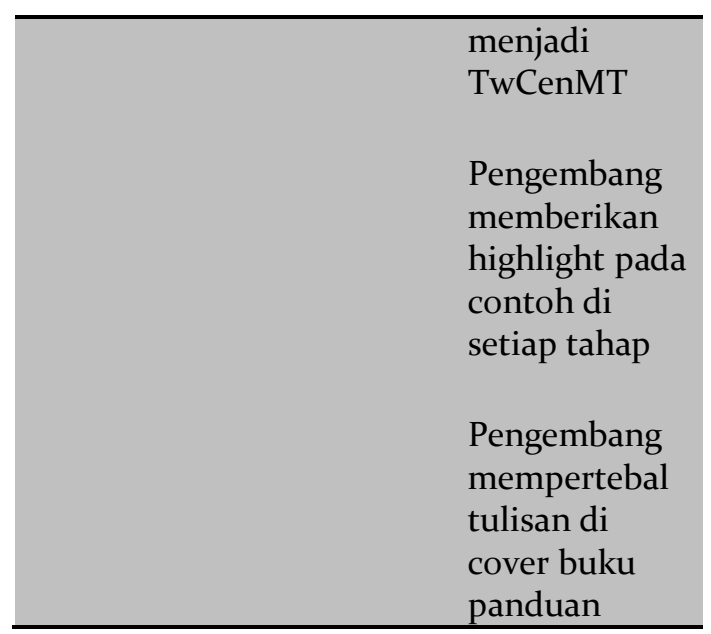

Pada tahap evaluasi satu-satu atau face-to-face tryouts, pengembang mengujicobakan produk pada tiga orang dosen FIP UNJ dari tiga program studi yang berbeda, yaitu Bapak Risa Sontosa dari Prodi Pendidikan Masyarakat, Ibu Wening Cahyawulan dari Prodi Bimbingan dan Konseling, serta Desi Rahmawati dari Prodi Manajemen Pendidikan. Hasil face-to-face tryouts tersebut tersaji pada tabel rekapitulasi berikut:

Tabel 7 Rekapitulasi Hasil Expert review

\begin{tabular}{lc}
\hline \multicolumn{1}{c}{ Responden } & Nilai Rata-Rata \\
\hline Risa Sontosa & 3,6 \\
Wening & 3,9 \\
Cahyawulan & \\
Desi Rahmawati & 3,9 \\
Rata-Rata & 3,8 \\
Keseluruhan & \\
\hline
\end{tabular}

Dari hasil face-to-face tryouts tersebut, didapatkan nilai rata-rata sebesar 3,8 Hal ini menunjukkan panduan dinilai sangat baik menurut sudut pandang pengguna dan mampu memandu pengguna dalam mendesain konten e-learning, khususnya dalam hylearn. Berikut ini ialah saran yang diperoleh dari hasil face-to-face tryouts:

1. Samakan istilah yang dikenal oleh dosen dengan yang berada di panduan, contoh : tujuan pembelajaran diubah menjadi capaian pembelajaran

2. Istilah-istilah yang kurang familiar ditambahkan kembali di glosarium

3. Penulisan daftar glosarium dapat lebih konsisten 
4. Penjelasan tentang e-learning di FIP UCAPAN TERIMA KASIH ditaruh di awal/pengantar

5. Tambahkan identitas tim penyusun dalam isi panduan

6. Tingkatkan konsistensi penggunaan istilah

7. Tekankan penggunaan panduan untuk hylearn

\section{SIMPULAN}

Produk hasil yang dikembangkan pada penelitian pengembangan ini ialah panduan mendesain konten e-learning untuk dosen di Fakultas Ilmu Pendidikan, Universitas Negeri Jakarta berbentuk buku dan leaflet. Buku dan leaflet panduan ini dikembangkan berdasarkan analisis kebutuhan dosen di FIP UNJ, sehingga produk dapat dijadikan sebuah alternatif sumber belajar dosen dalam hal mendalami proses mendesain konten e-learning di FIP UNJ. Pengembangan buku panduan ini dilakukan secara sistematis dengan mengacu pada model Rowntree, yang mencakup tiga tahapan besar yaitu tahap perencanaan, tahap persiapan penulisan, dan tahap penulisan dan penyuntingan.

Reviu ahli materi menyatakan bahwa Panduan Mendesain Konten E-learning secara umum bila ditinjau dari aspek materi dinilai sangat baik, dengan skor 3,6 dan layak untuk digunakan. Reviu ahli media menyatakan bahwa Panduan Mendesain Konten E-learning secara umum bila ditinjau dari aspek media dinilai baik, dengan skor 3,1 dan layak untuk digunakan. Uji coba face-to-face tryouts yang melibatkan tiga orang dosen FIP UNJ dari program studi BK, PenMas dan MP menyatakan bahwa Panduan Mendesain Konten E-learning secara umum dinilai sangat baik dengan skor 3,8 dan layak untuk digunakan.

Dengan demikian, berdasarkan prosedur tahapan mengembangkan panduan serta uji coba yang telah dilakukan, maka dapat dinyatakan bahwa panduan mendesain konten e-learning yang dikembangkan memiliki kualitas yang baik dan dapat digunakan untuk memfasilitasi dosen di FIP UNJ untuk belajar mendesain konten e-learning yang sesuai dengan kaidah.
Terima kasih saya ucapkan kepada dosen pembimbing, keluarga, teman-teman dan pihak-pihak yang telah mendukung selama proses penelitian berlangsung.

\section{DAFTAR PUSTAKA}

Januszweski, Alan \& Molenda, Michael. (2010) Educational Technology: A Definition with Commentary, New York: Routledge,

Rowntree, Derek. (1994) Preparing Materials for Open, Distance, and Flexible Learning, London: Kogan Page

Hanim, Masita Raisa, Purwaningsih, Endang \& Widjianto. (2014) Pengembangan Buku Panduan untuk Guru dalam Merencanakan Pembelajaran Fisika Berbasis Blended Learning Menggunakan Moodle, Malang: Jurusan Fisika FMIPA Universitas Negeri Malang 